EPJ Web of Conferences 110,01049 (2016)

DOI: $10.1051 /$ epjconf/201611001049

(C) Owned by the authors, published by EDP Sciences, 2016

\title{
THERMAL MODE OF TANKS FOR STORAGE FUEL OF THERMAL POWER PLANTS AND BOILER WITH THE INFLUENCE OF ENGINEERING FACILITIES IN THE AREA OF THEIR PLACEMENT
}

\author{
Polovnikov V.Yu. ${ }^{1,}$, , Makhsutbek F.T., Ozhikenova Zh.F. \\ ${ }^{1}$ National Research Tomsk Polytechnic University, 634050 Tomsk, Russia
}

\begin{abstract}
This paper describes the numerical modeling of heat transfer in the area placing of the tank for storage fuel of thermal power plant and boiler with the influence of engineering construction. We have established that the presence of engineering structures in the area of placing of the tank for storage fuel of thermal power plant and boiler have little effect on the change of heat loss.
\end{abstract}

\section{Introduction}

The research of thermal modes of different objects (a residential building [1], a hot water pipes [2], a fuel storage tank et al.) is an important problem.

Currently, the method of calculation and design of a fuel storage tank does not take full account of all processes in a tank, that occur during the preparation of a fuel oil for combustion.

One of the most promising approaches to research of different equipment is the use of a computer programs. They take into account various effects and processes in the system of heat transfer.

The objective is the mathematical modeling of the thermal loss of fuel storage tank and numerical analysis of thermal conditions of the tank.

\section{Problem statement}

We consider a typical vertical cylindrical steel underground tank. Figure 1 shows a schematic representation of the field solution of the problem. For the domain under consideration (Fig. 1) we solve a 2D linear and stationary problem of heat transfer in conditions of an engineering structure effect.

For decisions are taken into account engineering construction in the area of the tank.

Formulating the problem, we used the following assumptions:

1. The heat transfer processes in the internal and the external environment are disregarded.

2. Thermophysical characteristics of materials used in the analysis are constant and known values.

3. There is an ideal thermal contact conditions at the boundaries.

a Corresponding author: polov@tpu.ru 
4. The heat in the decision domain (Fig. 1) is transferred only by conduction.

The listed assumptions, on the one hand, do not impose constrains of principle on the physical model of the system (Fig. 1), but, on the other hand, allow one to simplify in a certain manner the algorithm and method for solving the posed problem.

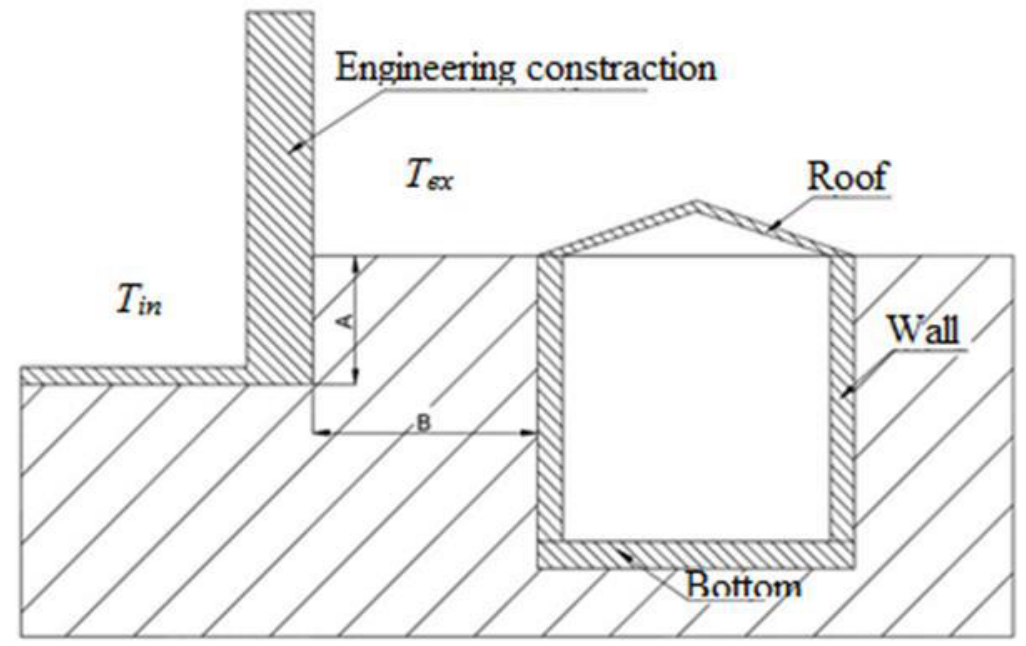

Figure 1. Schematic representation of the field solution of the problem.

\section{Mathematical model}

The processes of heat transfer to the object under consideration (Fig. 1) will be described by the following equation:

$$
\begin{gathered}
\nabla^{2} T_{\mathrm{ins}}=0 ; \\
\nabla^{2} T_{\mathrm{g}}=0 ; \\
\nabla^{2} T_{\mathrm{f}}=0 . \\
T_{\mathrm{ins}, 1}=T_{\mathrm{oil}}=\mathrm{const} . \\
\lambda_{\text {ins }} \operatorname{grad}\left(T_{\mathrm{ins}, 2}\right)=\lambda_{\mathrm{g}} \operatorname{grad}\left(T_{\mathrm{g}, 2}\right) ; T_{\mathrm{ins}, 2}=T_{\mathrm{g}, 2} ; \\
\lambda_{\mathrm{g}} \operatorname{grad}\left(T_{\mathrm{g}, 3}\right)=\lambda_{\mathrm{f}} \operatorname{grad}\left(T_{\mathrm{f}, 3}\right) ; T_{\mathrm{g}, 3}=T_{\mathrm{f}, 3} . \\
-\lambda_{\mathrm{g}} \operatorname{grad}\left(T_{\mathrm{g}, 4}\right)=\alpha\left(T_{\mathrm{g}, 4}-T_{\mathrm{ex}}\right) ; \\
-\lambda_{\mathrm{f}} \operatorname{grad}\left(T_{\mathrm{f}, 5}\right)=\alpha\left(T_{\mathrm{f}, 5}-T_{\mathrm{ex}}\right) ; \\
-\lambda_{\mathrm{f}} \operatorname{grad}\left(T_{\mathrm{f}, 6}\right)=\alpha\left(T_{\mathrm{f}, 6}-T_{\mathrm{in}}\right) ;
\end{gathered}
$$




$$
\begin{aligned}
& -\lambda_{\mathrm{f}} \operatorname{grad}\left(T_{\mathrm{f}, 7}\right)=\alpha\left(T_{\mathrm{f}, 7}-T_{\mathrm{in}}\right) \\
& \operatorname{grad}\left(T_{\mathrm{g}}\right)=0, x \rightarrow \pm \infty, y \rightarrow-\infty \\
& \operatorname{grad}\left(T_{\mathrm{f}}\right)=0, x \rightarrow \pm \infty, y \rightarrow+\infty
\end{aligned}
$$

\section{Method of solution and Initial data}

The system of equations (1)-(12) was solved by the finite element method [3, 4], using the Galerkin approximation [5]. The investigations were carried out on a nonuniform finite-element mesh. The number of elements was chosen from conditions of convergence of solution, the mesh was made denser by the Delaunay method [5].

In spite of the fact that in statement of the problem it was assumed to use an infinite-size domain (expressions (11) and (12)), in the numerical analysis of heat loss we used a finite size of calculation domain. The sizes of the calculation domain were chosen on the basis of a series of preliminary numerical experiments in such a manner that the relative change of the temperature gradients at the domain boundary does not exceed $0.5 \%$.

The analysis was carried out for a vertical steel tank with the thermal insulation of mineral wool (50 mm thick). The temperature of an oil was $T_{\text {oil }}=353^{\circ} \mathrm{K}$. The ambient temperature $T_{\text {ex }}$ taken equal to the average air temperature for the heating period in the city of Tomsk. The air temperature inside the engineering structure was equal to $T_{\text {in }}=293.15 \mathrm{~K}$. The coefficients of heat transfer in all variants of the numerical analysis were $\alpha=15 \mathrm{~W} /(\mathrm{m} 2 \cdot \mathrm{K})$.

The distance from the external tank insulation to the basement was $B=20 \mathrm{~m}$, and the deepening of the foundation was $A=2 \mathrm{~m}$ (Fig. 1).

Table 1 contains values $[2,4]$ of thermophysical characteristics, which were used in the numerical investigations of thermal conditions of the system under consideration (Fig. 1).

Table 1. Thermal properties of materials.

\begin{tabular}{|c|c|c|c|}
\hline Material & $\begin{array}{c}\text { Density, } \\
{\left[\mathbf{k g} / \mathbf{m}^{\mathbf{3}}\right]}\end{array}$ & $\begin{array}{c}\text { Thermal conductivity, } \\
{[\mathbf{W} /(\mathbf{m} \cdot \mathbf{K})]}\end{array}$ & $\begin{array}{c}\text { Heat capacity, } \\
[\mathbf{J} / \mathbf{( k g} \cdot \mathbf{K})]\end{array}$ \\
\hline Mineral wool & 150 & 0.046 & 840 \\
\hline Reinforced concrete & 2200 & 1.54 & 887 \\
\hline Ground & 1835 & 1.42 & 1155 \\
\hline
\end{tabular}

\section{Results of numerical simulation}

The main results of numerical modeling of thermal conditions of the system under consideration (Fig. 1) are listed in Table 2 and in Fig. 2-4.

Table 2 lists the results of numerical experiments of the heat loss of a vertical cylindrical steel underground tank $\left(Q_{1}\right.$ is the heat loss without engineering construction and $Q_{2}$ is the heat loss with considering engineering construction).

Table 2. Results of the calculation of heat loss.

\begin{tabular}{|c|c|c|c|c|}
\hline \multirow{2}{*}{ Month } & $\boldsymbol{T}_{\mathrm{ex}},\left[{ }^{\circ} \mathrm{C}\right]$ & $\boldsymbol{Q}_{\mathbf{1}},[\mathbf{k W}]$ & $\boldsymbol{Q}_{2},[\mathbf{k W}]$ & $\frac{\boldsymbol{Q}_{1}-\boldsymbol{Q}_{2}}{\boldsymbol{Q}_{1}} \mathbf{1 0 0 \%}$ \\
\hline September & +9.2 & 97.451 & 97.638 & 0.192 \\
\hline
\end{tabular}




\begin{tabular}{|c|c|c|c|c|}
\hline October & +0.9 & 109.140 & 109.103 & 0.034 \\
\hline November & -10.4 & 124.727 & 124.719 & 0.006 \\
\hline December & -17.5 & 134.281 & 134.730 & 0.333 \\
\hline January & -19.2 & 136.641 & 136.866 & 1.334 \\
\hline February & -16.7 & 133.157 & 133.419 & 0.196 \\
\hline March & -10.1 & 124.090 & 124.314 & 0.180 \\
\hline April & -0.1 & 110.264 & 110.490 & 0.205 \\
\hline May & +8.6 & 98.275 & 98.462 & 0.190 \\
\hline June & +15.3 & 89.021 & 89.208 & 0.210 \\
\hline
\end{tabular}

Validity and reliability of the obtained results follow from tests of the methods for convergence and stability of solutions on multiple meshes, fulfillment of the energy balance conditions at boundaries of the calculation domain. The relative calculation error in all versions of the numerical analysis did not exceed $0.5 \%$, which is acceptable for investigations of thermal conditions of the system under consideration (Fig. 1).

Figures 2 and 3 show the typical temperature fields in the area of storage tanks for fuel thermal power plants and boiler plants in the absence of nearby engineering structures (Fig. 2) and, if it available (Fig. 3).

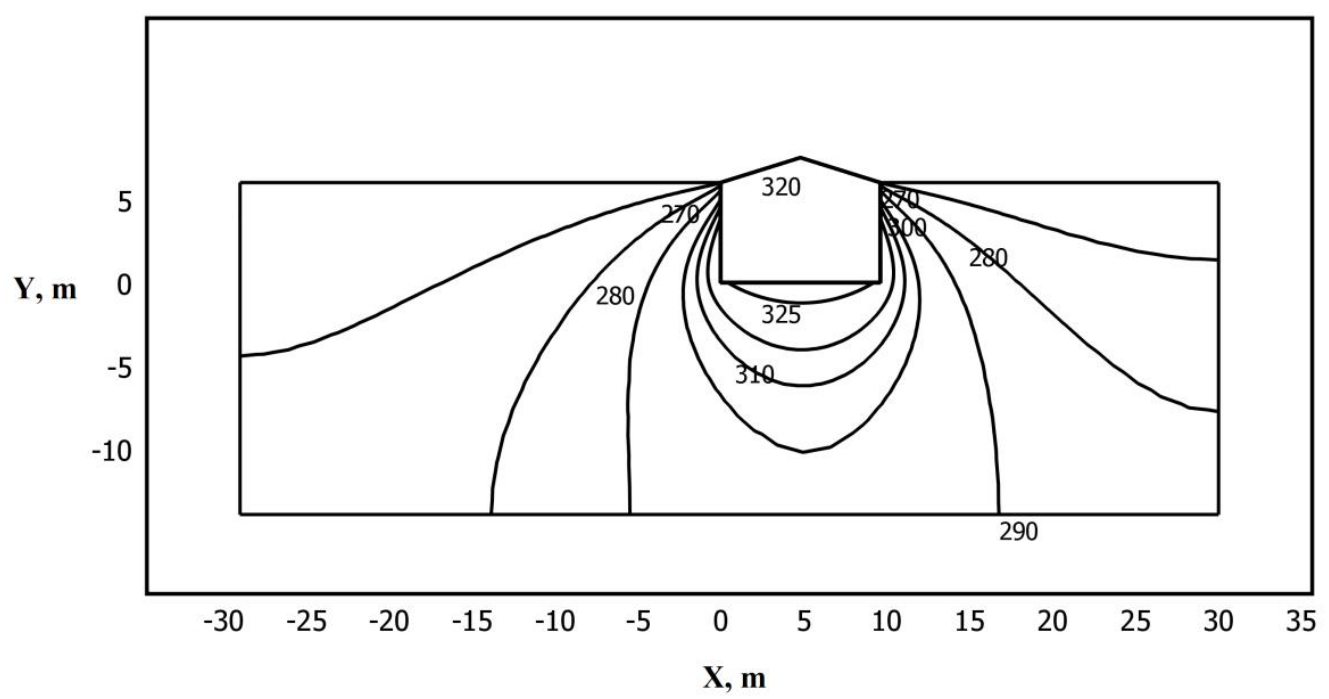

Figure 2. Typical temperature field in the zone of the storage tanks for fuel thermal power plants and boiler at ambient temperature $-40{ }^{\circ} \mathrm{C}$. 


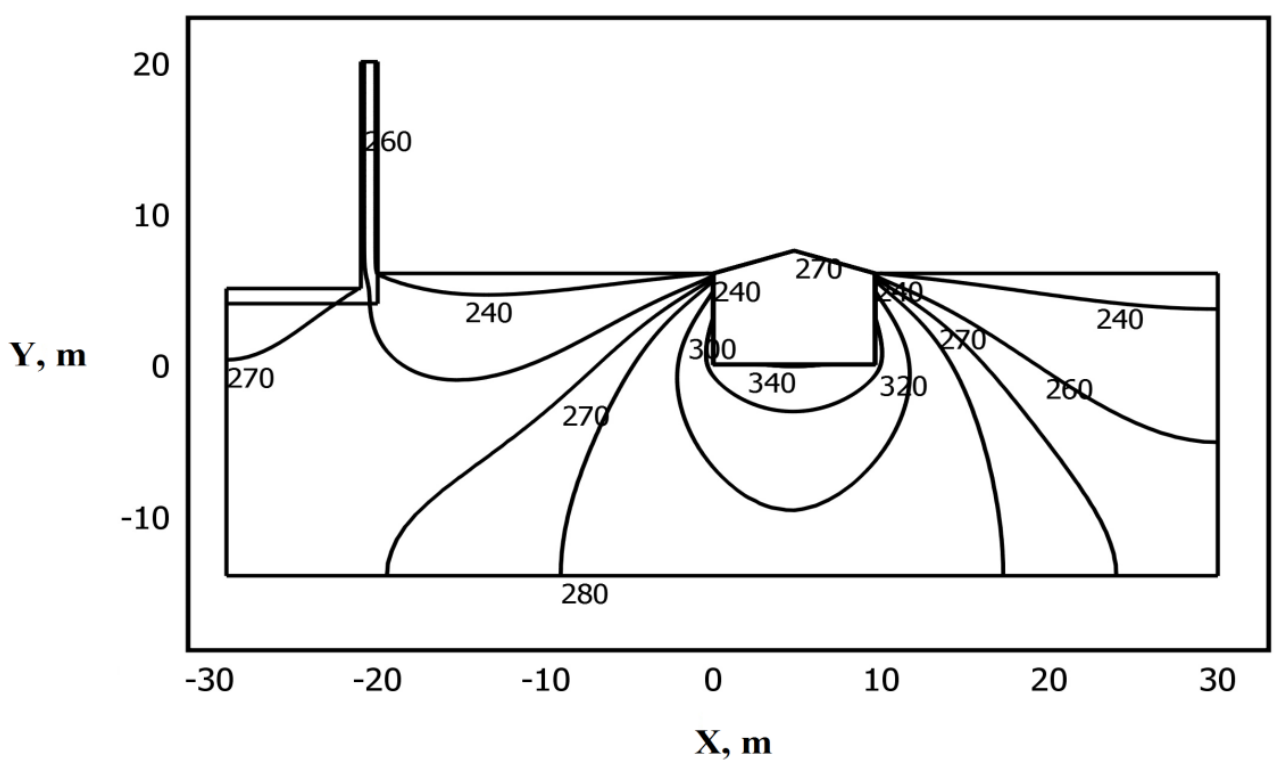

Figure 3. Typical temperature field in the zone of the storage tanks for fuel thermal power plants and boiler at ambient temperature $-40^{\circ} \mathrm{C}$, taking into account the impact of engineering structures.

\section{Conclusion}

Numerical analysis of heat losses of storage tanks for fuel thermal power plants and boiler plants (Table 2 and Fig. 2-4) indicate that the presence of engineering structures in the area of their distribution have little effect on the change of heat loss, so you can ignore this indication.

\section{Notations}

$T$ - temperature, $\mathrm{K} ; \lambda$ - coefficient of thermal conductivity, $\mathrm{W} /(\mathrm{m} \cdot \mathrm{K}) ; \alpha$ - the heat transfer coefficient, $\mathrm{W} /\left(\mathrm{M}^{2} \cdot \mathrm{K}\right)$.

Indexes: ins - a layer of heat insulation; $\mathrm{g}$ - ground; oil - oil; $\mathrm{f}$ - foundation engineering structure; in - internal; ex - external; 1 - the inner surface of the tank insulation; 2 - the boundary between "shell of tank - ground"; 3 - the boundary between "soil - foundation engineering structure"; 4 - the boundary between "soil - environment"; 5 - the boundary between "soil - engineering structure"; 6 the boundary between "foundation - the air inside the engineering structure"; 7 - the boundary between "basement floor - the air inside the engineering structure".

\section{References}

1. S. Korniyenko, Procedia Eng., 117, 1 (2015)

2. V.Yu. Polovnikov, E.V. Gubina, J. Eng. Phys. Thermophys., 87 (2014)

3. A.L. Garcia, Numerical methods for physics (Prentice Hall, New York, 2000)

4. V.Yu. Polovnikov, E.S. Glazyrin, European Physical Journal Web of Conferences, 82 (2015)

5. J. N. Reddy An Introduction to Nonlinear Finite Element Analysis (Oxford University Press, New York, 2004) 